\title{
The Challenge of the Future as Viewed by a Practicing Range Technician ${ }^{1}$
}

\author{
ARNOLD HEERWAGEN \\ Range Conservationist, Soil Conservation Service, U.S. \\ Department of Agriculture, Denver, Colorado
}

\section{Range Technician's Work}

My fellow panel members have given their views of the challenging future in range management. They were speaking from the firmly entrenched and welldefined positions of a rangeland owner, educator, and researcher.

Today's practicing range technician has no well-defined niche. His varied duties in governmental agencies and in the livestock and related industries defy simple description. Despite this, most range technicians have some traits and duties in common. Here are a few:

1. So far, "he is a he".

2. He is generally a college graduate with a degree in range management or at least with some course work in range management and related subject matter. 3 . He's generally a staff officer rather than an administrator. If he becomes an administrator he no longer is called a practicing range technician.

4. He generally spends at least half of each year outdoors.

5. Nowadays the majority of his clan don't wear big hats, high heeled boots, or roll their own cigarettes. There are several documented reports concerning range technicians who don't wear any hats at all.

6. He specializes in sack lunches but rarely sleeps outdoors.

7. He's an expert on pickup trucks and jeeps, but with few exceptions, a mediocre horseman.

1 Presented at the symposium on "How We May Meet the Challenge of the Future" during the Seventeenth Annual Meeting, American Society of Range Management, Wichita, Kansas, February 10-14, 1964.
8. He's somewhat uncertain about the meaning of such terms as free martin, ridgeling, "mothering up", and diamond hitch.

9. He gives the impression of knowing the name of about twothirds of the plants in his locality.

10. His artistic bent is evidenced by his affinity for plant identification manuals containing numerous sketches and colored prints.

11. On occasion he may be observed hovering around the fringe of a range research project, but rarely is he an integral part of it. He's gradually becoming less suspicious of the "researcher". Too often, however, he still doesn't know what the researcher has done, is doing, or plans to do.

12. He now does, or at one time has done, a considerable amount of range survey work-once upon a time with a horse and plane table, but now with a pickup and aerial photograph.

13. Depending on whom he's working for, he may rarely or frequently have to contact ranchers. A minority of his clan hold out to the bitter end in trying to avoid such contacts. However, if face-to-face confrontation is inevitable, opening inquiries have to do with rainfull or the prices of calves or lambs. 14. He's always wondering when the bosses are going to change methods and procedures. If he has been on the job for more than 20 years, this has happened at least five times.

15. In our profession, he's the individual who does most of the grunting and groaning in blending theory and practice right out on the range.
The real "old timer" range technician has weathered a number of basic changes in the nature of his duties and views inevitable future changes with varying degrees of trepidation. He can remember the time when one of his principal duties was simply to list the relative amounts of plants on the ground. At some later date in the office, he'd compute carrying capacity, zealously carrying all computations to three decimal points. In those days, his major concern, as expressed by one of my colleagues, was primarily answering the question, "what have we here?"

In time this same technician was directed to answer two additional questions. These were "in what shape is what we have here, and what's happening to what is here?" After spirited ideological interchange the answers to these two questions finally became known as range condition or range condition and trend. However, some technicians had to take a prior step. They had to decide what kind of rangeland they were looking at before answering the foregoing questions. For these technicians the various kinds of rangeland became known as range sites. Thus, through the years, range inventory and analysis processes have broadened in scope and increased in complexity.

Progressively a great variety of other duties have been added to his job. The nature and number of these duties have varied materially among the employing agencies, but most technicians, in addition to survey, do some or all of the following:

1. Develop or assist in the development and application of grazing management plans.

2. Plan or assist in planning and applying a variety of range conservation practices such as seeding, brush control, and erosion control.

3. Assist in coordinating grazing 
use with other rangeland uses, such as wildlife, recreation, forestry, and watershed protection. 4. Assist in the development and adaptation of range techniques and procedures to local field situations.

5. Conduct evaluation studies pertaining to the performance of range conservation practices.

The broadening scope and greater complexity of the range technician's job precludes his being an expert in every phase of his work. Frequently, he'll tend to concentrate on one or two specialties and try to become reasonably expert in them. Thus there are range technicians that are adept at brush control or seeding, for example, but have only average skills in some other aspects of their total job.

Before conjecturing how such a technician feels about the future, let's briefly speculate on the current status of his knowledge and his attitude toward his job.

Presumably his present knowledge, his confidence in his ability, and his guide to action result from a pooling of his academic and on-the-job training, his knowledge of range research results, his field experience, and the policies and procedures prescribed by his employer. He's aware that at least some of the procedures that he uses are a matter of sharply divided opinion within his profession and between his profession and some rangeland users. He has witnessed repeated assaults on some of the long-standing "sacredcow" concepts that have developed among professional rangemen. He's seen some of these concepts teeter on their foundations and may even be a contributor to the teetering process. If he's a genuine free thinker he's skeptical of some of the earlier answers and impatient for new ones.

Now let's try to look into the future through the eyes of this kind of practicing range technician. Obviously, it would be extremely presumptuous for one technician to speak for his entire group. I hope those range technicians with an outlook in direct contrast to mine will find a suitable means for rebuttal.

In facing the challenges of the future, particular emphasis will need to be given to:

1. Meeting the challenge of alternative uses of rangeland.

2. Improved rancher-technician working relationships.

3. Improving rangeland surveys and appraisals.

4. Increasing the effectiveness of range conservation practices. 5. Identifying urgent needs for additional knowledge.

6. Realistically coming to grips with rangeland economics.

\section{The Challenge Of Alternative Land Uses}

For some time range technicians and ranchers have seen rangelands used for many purposes other than solely for grazing by domestic livestock. Of particular significance is their use for wildlife, watersheds and recreation inasmuch as these uses are frequently concomitant with grazing by domestic livestock. Generally one use is dominant, and other uses are secondary. Multiple use of land is, of course, not a new endeavor. It has been a guiding principle on some Federally owned lands for several decades. It has been deliberately or unintentionally in effect on a significant number of ranches for extended periods of time. Consider, for example, the number of livestock ranches that always have had simultaneous grazing use by big game animals. No doubt such uses will mushroom in the future, both on Federally owned and on private rangelands. Probably a significant number of ranchers will not want to use their lands for public hunting and recreation purposes. However, the number of ranches that have deliberately planned for these additional land uses and are realizing an income from them is rapidly increasing.

In the future, range technicians will need to be better equipped to contribute their knowledge to existing and new demands of rangelands.

\section{Improving Rancher-Technician Working Relationships}

Don't you think that the quality and quantity of range management would improve if ranchers and range technicians really understood the others' language and objectives?

In the early days of professional range management work many range technicians rarely, if ever, worked directly on the range with ranchers. Many business transactions between rangeland administrators and rangeland users were conducted in the office or by correspondence. In this setting it's not surprising that most ranchers did not understand what range technicians were doing and were suspicious of why they were doing it. Over the years this extreme isolationism has ameliorated somewhat but still falls far short of togetherness.

The best place to improve rancher-technician working relationships is in the pasture or the grazing allotment. Range management is in part a science, but its effective application is an art directly dependent upon the actions of people. It is in the pasture or allotment that technicians can best demonstrate their concepts of range management. Here also, ranchers can best explain the nature and needs of their operating units and contribute the results of their practical experience.

Decisions based on mutual understanding of problems and on mutually agreed upon courses of action stand a good chance of being effectively carried out. The limited number of trained range technicians available is now a limitation on the amount of joint 
rancher-technician field work that can be done. However, a major increase in such work is a necessity, a challenge, and a bright hope for the future.

\section{Improving Rangeland Surveys And Appraisals}

While the early-day range vegetative type surveys served some useful purposes, in my opinion they only partially meet the needs of today and the future. These surveys delineated vegetative types, recorded plant composition, located cultural features, and briefly noted such features as soil condition, erosion, presence of rodents, etc.

More recently many range surveys determine and record range condition and trend or range site and condition. I feel that such surveys provide a better basis for management decisions than range vegetative type surveys, but they, too, fall short of meeting the total short-term and long-term needs of the several rangeland uses. In fact, no single survey can be expected to meet total needs for all time. Surveys based solely on vegetation are inadequate for these reasons:

1. Some rangelands have been, are now, and will in the future be used for purposes other than solely for grazing by domestic livestock. Vegetative surveys fail to provide some of the basic land resource data needed to determine suitability and to plan comprehensive programs for all of these alternative uses.

2. In terms of grazing use a vegetative survey progressively loses utility with passage of time. Plant composition, range condition, and particularly plant yields are subject to significant fluctuation in time. Therefore, data from such range surveys of previous years are not valid for current and future day-to-day decisions on grazing management.

If surveys of rangeland are, in fact, to meet the needs of alternative land uses and, in addition,

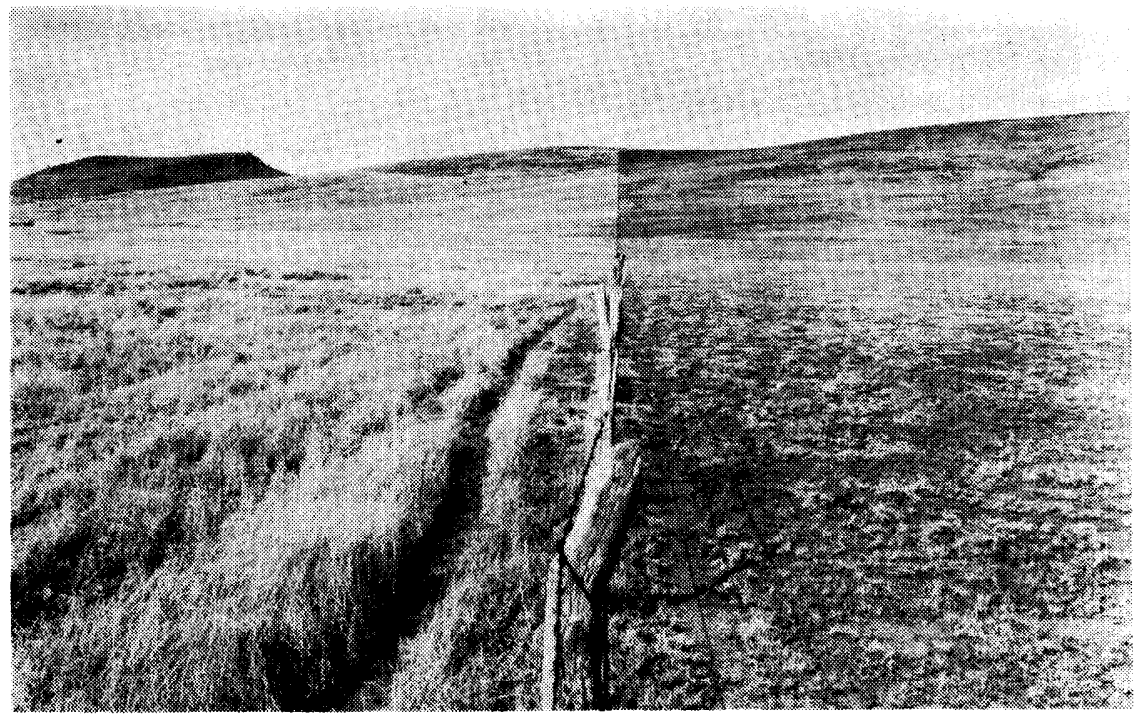

Figure 1. Appraisal of current range conditions is needed for day to day management decisions.

meet current needs for decisions required for grazing management, two types of surveys will be required. One of these will, in effect, be some form of basic land resource survey. The other will be an appraisal of range conditions which will be repeated as needed to provide up-to-date information for management decisions (Fig. 1).

Standard soil surveys now in use by several agencies have lasting utility as one type of basic land resource survey. Detail of mapping can be geared to best fit the needs of existing or forseeable future land uses. Such surveys provide much of the basic physical data needed in evaluating some aspects of alternative rangeland uses. For grazing use by domestic livestock particular attention can be given to the preparation of soil mapping legends that will result in mapping units having maximum utility for (1) delineation of areas having similar potentials for grazing use, and (2) rangelands suitable for various types of range conservation treatment.

In the absence of basic land resource surveys, the alternative would seem to be a series of independent special purpose surveys for each of the various land uses. This would involve a con- siderable duplication of time and effort in the collection of physical resource data.

\section{Improving The Effectiveness Of Range Conservation Practices}

Studies show that burrowing rodents on rangelands may move 20 to 40 tons of soil per acre. Some anthills in eastern Utah weigh up to 400 pounds. Even the lowly earthworm may bring several tons of earth per acre up to the soil surface. This industrious activity by native fauna has made little impression on those individuals who feel that "The dirt must fly" if the range is to be improved. Thus the bulldozer and the disc have become symbols of range improvement in action-as have the astringent smell of herbicides and the wellworn discs of rangeland drills. Before anyone jumps to the conclusion that here indeed is an advocate of pristine nature as the ultimate goal of range management, let me emphatically state that this is in no sense true. Judicious use of earth moving equipment, brush control devices, and range seeders is for many rangelands essential to improvement in a reasonable period of time, even if, in some cases it involves the complete destruction of the existing native plant 
cover and its replacement by planted covers. Rather this is a plea for the kind of range improvement programs that:

1. First consider the overall needs and management objectives for the rangeland involved. 2. Consider the overall needs of the ranch enterprise as a unit rather than simply the needs of an individual pasture.

3. Then plan and design a combination of practices, including the all-important grazing management practices, that will best meet the immediate and longterm needs of the land and the operating unit.

Haven't we frequently been guilty of a piecemeal approach to range improvement? Can't you think of many instances where individual range improvement measures that were initially successful but ultimately failed because the essential complementary practices were not applied simultaneously?

We now are or should be past the point where our approach toward range improvement is centered around the piecemeal alleviation or cure of an individual rangeland ill. Shouldn't we first determine the overall state of health and the total needs of sick rangelands and then prescribe treatment in accordance with such total needs?

\section{Identifying Urgent Needs For Additional Knowledge}

We appreciate the effort that research workers and educators have made to date; however, we urgently need a continuation and expansion of these efforts. Some of our most urgent needs for further knowledge are:

1. Plant Physiology: We realize that you are making tremendous strides in determining how plants grow. However, much of this work has been done with dicotyledonous plants such as beans and peas. Can you do more work dealing specifically with the physiology of range grasses and brush species? We find that knowledge of growth habits and characteristics of the plants we actually work with on the range is important in discussions with rangeland operators on the effects of grazing, plant competition, plant succession, and the control of undesirable species.

2. Plant-Soil-Water Relationships: You as research workers, and we, as range technicians, have made considerable progress in associating certain plants and plant communities with certain environments and specific kinds of soil. However, we still need to know much more about why these differences exist. What are the significant characteristics of the soil, macroenvironment, and microenvironment that cause plant community differences? We feel that your findings will have direct utility in field application. Knowledge of this kind should help us to do a better job of appraising plant community potentials and in assessing the nature and rate of range condition changes. Without it our diagnosis and prognosis of "what's happening to what we have here" will continue to be based on an excessive degree of empirical judgment.

We appreciate your findings on the relative water requirements of range plants. Unfortunately, data are available for only a few species. Many manmade interests are now competing and will in the future more intensively compete with range plants for water. In the face of this intensified competition, we are reaching the point where we can't afford to waste water on rangeland plants that don't serve a useful purpose or that provide a poor quality or quantity of forage in terms of their potential.

3. Range Fertilization: Here indeed is a practice about which there are widely divergent viewpoints and conflicting evidence. Extreme viewpoints vary from those who feel we can't even begin to assess the potential pro- ductivity of rangelands without first applying fertilizers, to those who feel that fertilization has no present or future home on the range. Our scant knowledge of the actual nutrient requirements of most range plants continues to confound the issue.

Many range technicians are straddling the fence on this practice while awaiting developments. However, because the practice can be easily applied and has a ready appeal to many rangeland operators, its misuse in untried and unproven situations is not uncommon.

We are in urgent need of factual answers about fertilization on a number of additional kinds of rangeland. The problem is not so much whether the answers are positive or negative but rather, are they conclusive as shown by objective experimentation?

4. Predicting Forage Yields: If there is one single factor that causes the major problem in attaining proper grazing use of rangelands, it is the wide and unpredictable fluctuation in seasonal and annual forage production. This is not only a physical problem in maintaining rangeland resources but also a pressing economic problem to the rangeland user. Failure to make timely adjustments in stocking rates as dictated by available forage supplies is a two-edged sword. It too frequently results in excessive utilization in periods of low forage production. Conversely, ranchers, frequently cannot adjust stocking rates upward in time to efficiently utilize extra forage supplies in periods of high forage production.

If forage production could be predicted within reasonable limits in advance of the current growing season, the solution to the knotty problem of timely adjustments would be greatly facilitated. Within the past few years, research workers have given us some guidelines for several kinds of rangeland. We urge 
you to continue this high priority job, and to expand your efforts to different kinds of rangeland. 5. Control of Undesirable plants: Does it seem to you that in certain portions of the range country the brush problem is getting worse instead of better? This seems to be the opinion of some range technicians and ranchers despite a steady increase in acreage treated and in the efficiency of control methods. If this is correct, and I feel it is for some brush species and for some localities, why is this happening and what can we do about it?

It doesn't seem logical that the answer rests solely with a change in a single factor of the environment such as precipitation pattern or frequency of fires. Neither does it seem to depend solely on the intensity of grazing use. There is no denying the influence of repeated fires on plant communities. However, the differential response of species, sprouting ability of many species, and the persistence of some brush stands despite repeated fires cast doubt on this factor as the dominant influence for all brush problems. Research findings are continually pointing out kinds of rangeland where it is unrealistic to assume that, given time, grass will "choke out" brush. Apparently you are finding that the primary role of grass in the grass versus brush controversy is to help discourage rather than to completely prevent the reestablishment or invasion of new brush plants.

Is it possible that the cart is preceding the horse in our brush control efforts? Don't we still need to learn much more about the ecology of the individual species and the plant communities in which they live before we go much further with this practice? Existing brush stands pose a continuing limitation to increased productivity on millions of acres of range. Let's proceed with what we now know and speed up research on what we still need to know about brush and its control. I think most of us think in terms of reasonably effective control as opposed to complete and permanent eradication of brush. Many of us are reconciled to the need of periodic retreatment.

We also realize that many brush species provide valuable forage for domestic livestock. Many species have special value for wildlife food and cover. We need substantially more factual data on this problem.

6. Seeding: We hear talk of diametrically opposed viewpoints concerning the artificial revegetation of rangelands. It is apparent that there are differences of opinion on the relative merits of native versus introduced species for seeding rangelands, but I think the majority of range technicians, in line with our present state of knowledge, hold at least some of the following views:

a. There are millions of acres of rangeland that cannot be tilled for seedbed preparation with present methods and equipment.

b. There are millions of acres of rangeland that can be tilled and in need of seeding for

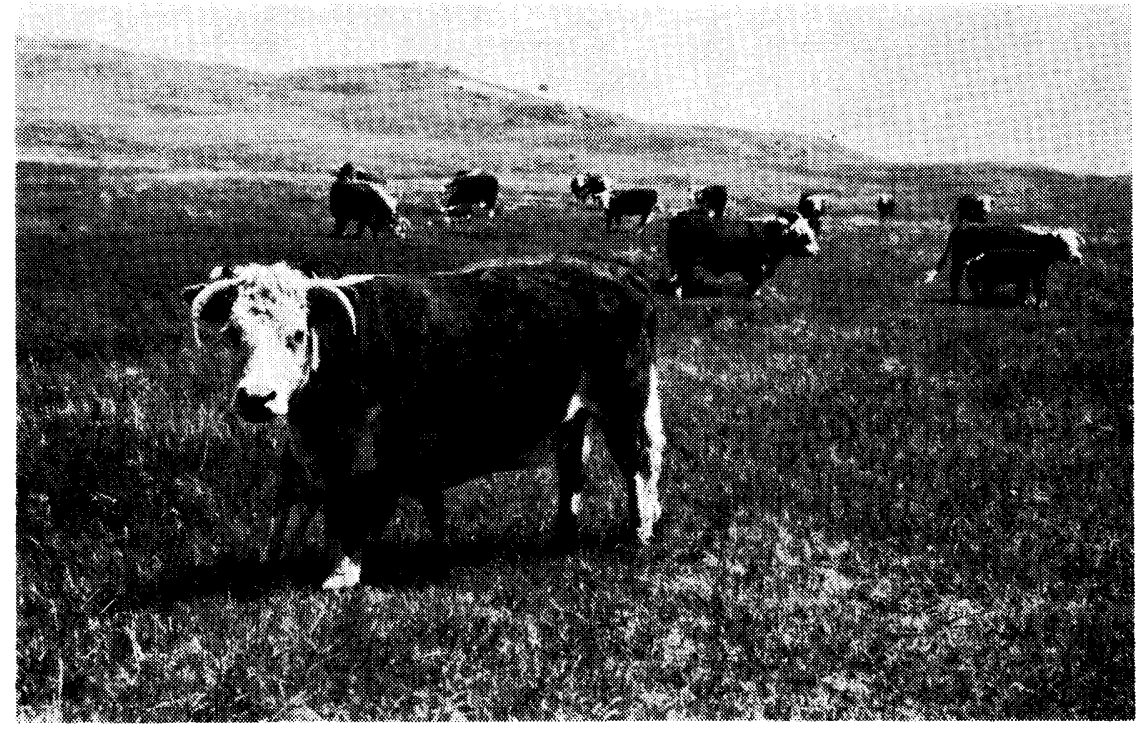

Figure 2. We urgently need convincing evidence that what we call good range management pays. which satisfactory methods of seeding are not known. Neither native nor exotic species produce satisfactory stands.

c. There are millions of acres of rangeland in need of seeding on which either native or introduced species can be seeded successfully. Which species are used should logically depend on the specific objective in mind and the particular forage needs of the individual ranch operating unit.

$\mathrm{d}$.There is a continuing and urgent need for additional research on methods and species adapted to the more difficult sites. Of particular concern are fine textured soils in semiarid and arid regions.

7. Grazing Intensity and Utilization Standards: Through the years the results of your grazing intensity studies have clearly pointed out the merits of moderate grazing use in terms of maintaining range resources and in economic returns from grazing. Your findings as to the merits of various grazing systems have been less consistent. For example, there now seems to be valid evidence endorsing deferred-rotation grazing for certain kinds of rangeland, but questioning its value for other kinds. 
I think many range technicians would agree that the identification and attainment of proper grazing use has been, is now, and will be in the future our most urgent problem in rangeland utilization by domestic livestock and big game animals. Despite supporting evidence from research studies and from an increasing number of individual ranch enterprises, we still have a long way to go in attaining universal application of this concept. Some of the things that will need doing to gain increasing acceptance of this practice include:

a. Additional research that will identify what constitutes proper grazing use for addi- tional kinds of rangeland, and for different seasons of use and different stages of plant growth.

b. Devising more effective ways of demonstrating the application of this practice to rangeland users in a manner that will convince them of its merits and benefits on their particular range operations.

\section{Realistically Coming To Grips With Rangeland Economics}

We urgently need additional convincing evidence that what we call good range management pays (Fig. 2). This evidence is needed in terms of the ranch enterprise as a whole rather than simply in terms of a single pasture or a single practice such as seeding or brush control. For maximum utility such evidence should go further than simply budgeting the enterprise-it should identify the kind and condition of rangeland involved and the nature and degree of grazing use in effect during the period of record.

I'm sure that our profession believes that good range management pays. We are gradually accumulating substantiating evidence. Let's give a high priority to fortifying this evidence to a point at which the proof is obvious. This will certainly be an effective "helper" in opening the gate to the future. 